\title{
Existe relação entre COVID-19 e infertilidade masculina?
}

\section{Is there a relationship between COVID-19 and male infertility?}

\author{
Juliana Stracci* \\ Júlia Teixeira Trezena de Brito** \\ Tatiana de Aguiar Tajra*** \\ Ravendra Ryan Moniz****
}

Resumo: A enzima conversora de angiotensina 2 (ECA2), expressa em diversos órgãos, como testículo, é receptor do SARS-CoV-2. Logo, investigou-se o risco potencial da infecção viral na fertilidade masculina, por meio de revisão narrativa no PubMed com os descritores "Infertility, Male", "SARS-CoV-2" e "COVID-19" cruzados pelo operador "AND". Dos 81 resultados, foram selecionados 10 artigos, pelos critérios de exclusão de fuga temática, revisões de literatura e editoriais. Dentre as alterações do sistema reprodutor masculino, foram encontrados desconforto testicular e escrotal, comprometimento seminal relacionado à modificação morfológica do espermatozoide, concentração, contagem e motilidade reduzidas, níveis séricos de testosterona (T), hormônio folículoestimulante (FSH) e hormônio luteinizante (LH) reduzidos, porém, não foi detectado SARS-CoV-2 em amostras seminais. Essas alterações seminais foram relacionadas a altos níveis de ECA2, interleucinas e outras citocinas nas células testiculares, que possuem maior expressão desses fatores se comparados às células pulmonares. Ademais, a taxa de ECA2 foi maior em homens inférteis, induzindo impactos reprodutivos do vírus pela ativação anormal da via ECA2. Portanto, sugere-se impacto na fertilidade masculina, todavia devido à atualidade do tema, é necessário que os estudos sejam concluídos.

Palavras chaves: Infertilidade Masculina. SARS-CoV-2. COVID-19.

Abstract: The angiotensin-2 converting enzyme (ACE2), expressed in several organs, including the testicles, is a SARS-CoV-2 receptor. Therefore, the potential risk of viral infection in male fertility was investigated through a narrative review on PubMed using the descriptors "Infertility, Male", "SARS-CoV-2" and "COVID-19" crossed by the operator "AND". From the 81 results, 10 articles were selected according to the exclusion criteria of thematic escape, literature review and editorial. Among the changes in the male reproductive system, testicular and scrotal discomfort, seminal commitment related to the morphological modification of sperm, reduced sperm concentration, count and motility, reduced serum testosterone ( $\mathrm{T}$ ), follicle-stimulating hormone (FSH) and luteinizing hormone (LH). However, SARS-CoV-2 was not detected in seminal samples. These seminal changes have been related to high levels of ACE2, interleukins and other cytokines in the testicular cells, which have higher expression of this factors when compared to lung cells. Therefore, an impact on male fertility is suggested, however, due to the topicality of the theme, it is necessary that studies are completed.

Keyword: Infertility, Male. SARS-CoV-2. COVID-19.

\footnotetext{
* Graduanda em Medicina pelo Centro Universitário São Camilo. E-mail: julianastracci@uol.com.br

** Graduanda em Medicina pelo Centro Universitário São Camilo. E-mail: jutrezena@gmail.com

*** Graduanda em Medicina pelo Centro Universitário São Camilo. E-mail: tati.tajra@gmail.com

**** Mestre em Urologia pela FAP - Hospital A. C. Camargo, Docente do Centro Universitário São Camilo, E-mail:

ravendra.moniz@prof.saocamilo-sp.br
} 


\section{INTRODUÇÃ̃O}

Recentemente, o patógeno viral SARS-CoV-2, causador da Doença por Coronavírus 2019 (COVID-19), tem se mostrado uma ameaça significativa à saúde pública mundial. Os primeiros casos da infecção viral foram relatados na cidade de Wuhan na China em dezembro de 2019 e, desde então, milhões de casos foram confirmados pelo mundo ${ }^{1-4}$.

A enzima conversora de angiotensina 2 (ECA2) desempenha papel crucial na fisiopatologia da COVID-19, uma vez que atua como receptor para a entrada do vírus nas células-alvo ${ }^{3-8}$. Do mesmo modo do SARS-CoV, a entrada do SARS-Cov-2 nas células humanas ocorre a partir da ligação da glicoproteína Spike (S) - enzima de superfície viral - com a ECA2 localizada na membrana celular da célula hospedeira. Com a mediação da serinoprotease transmembrana II (TMPRSS2), a região S1 da proteína $S$ se liga ao receptor, enquanto a região $S 2$ permite que o vírus se funda à membrana celular da célula-alvo ${ }^{3,7-8}$. Após a fusão, o genoma viral é liberado no citoplasma e as organelas da célula hospedeira passam a realizar replicação do RNA viral ${ }^{8}$.

Figura 1 - Diagrama esquemático do mecanismo de entrada de COVID-19, replicação viral e empacotamento de RNA viral na célula humana

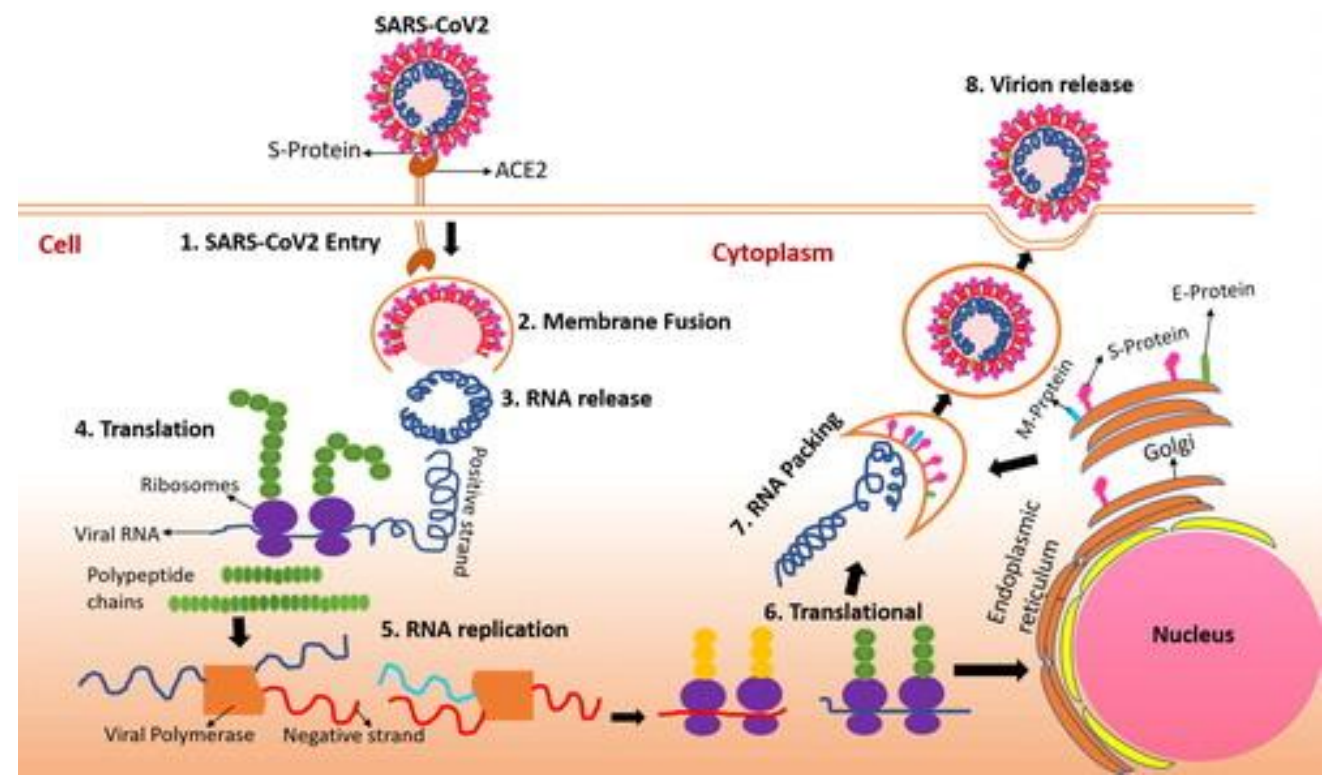

Fonte: Boopathi, 2020

A ECA2 é expressa em diversos órgãos e sistemas, como sistema respiratório, sistema digestivo, sistema cardiovascular e sistema geniturinário, incluindo os testículos ${ }^{1,4,6}$. Estudos prévios mostraram uma alta expressão do receptor ECA2 nos testículos, principalmente nas membras celulares de espermatogônias, células de Leydig e células de Sertoli ${ }^{7,9}$. A proporção de espermatogônias com expressão de ECA2 para população total de espermatogônias se assemelha à proporção de pneumócitos tipo II.

Como os estudos relacionados à COVID-19 ainda são recentes e, em grande parte, limitados, ainda há muitos aspectos da doença a serem considerados. Com base na fisiopatologia da doença, na alta expressão testicular de ECA2 e na epidemiologia, esta revisão objetivou investigar e reunir informações acerca do efeito da infecção por SARS-CoV-2 no sistema reprodutivo masculino e do seu risco potencial na fertilidade masculina.

\section{MÉTODOS}

O presente estudo é uma revisão narrativa realizada a partir de busca na base de dados PubMed, utilizando os descritores "Infertility, Male", "SARS-CoV-2" e "COVID-19" cadastrados no $\mathrm{DEcS}$ e cruzados pelo operador booleano "AND”. Não houve a aplicação de nenhum filtro específico 
para a busca, de forma que foram obtidos 81 resultados inicialmente. Após a leitura dos títulos e resumos e a aplicação dos critérios de inclusão (amostra masculina de pacientes que tiveram diagnóstico de infecção por SARS-CoV-2) e exclusão (fuga temática, revisões sistemáticas e não sistemáticas, relatos de caso e editoriais), foram selecionados 10 artigos para estudo.

\section{RESULTADOS}

Tabela 1 - Resumo dos resultados que mostram o impacto da infecção por SARS-CoV-2 na fertilidade masculina

\begin{tabular}{|c|c|c|}
\hline 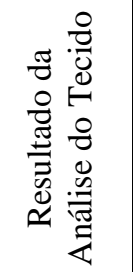 & & ' \\
\hline 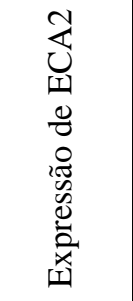 & & 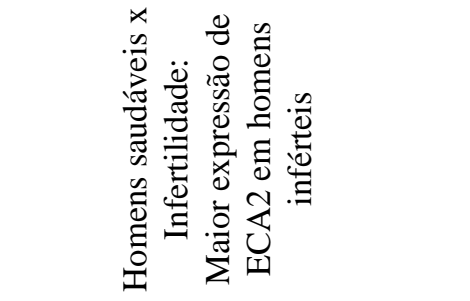 \\
\hline 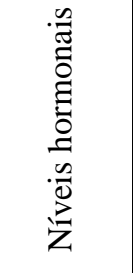 & & ' \\
\hline 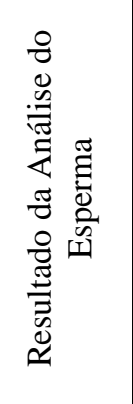 & 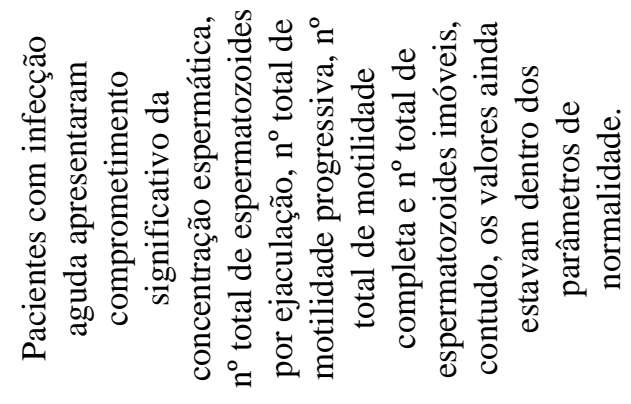 & ' \\
\hline 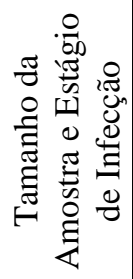 & 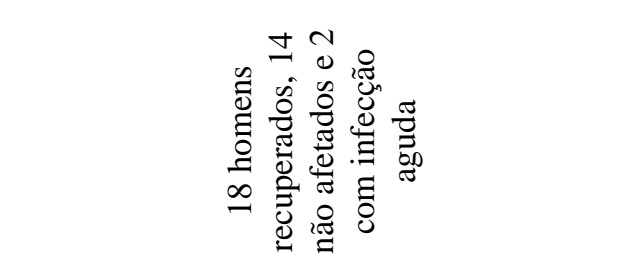 & 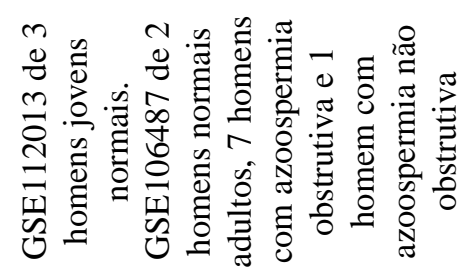 \\
\hline 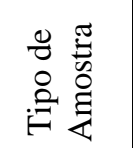 & 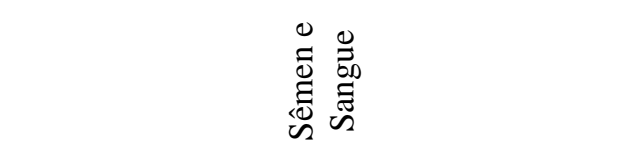 & 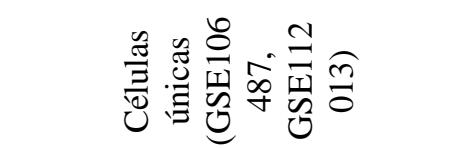 \\
\hline 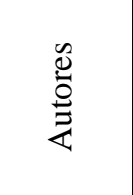 & 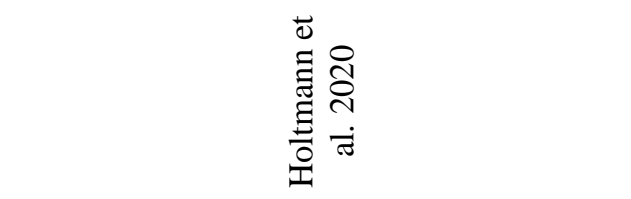 & 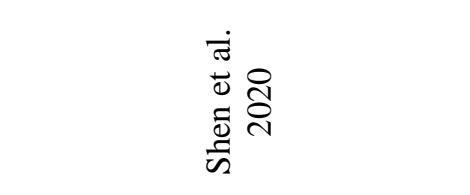 \\
\hline
\end{tabular}




\begin{tabular}{|c|c|c|}
\hline 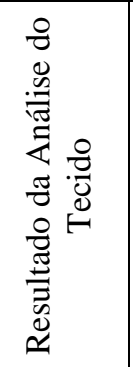 & ' & ' \\
\hline 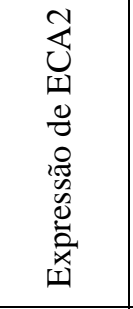 & ' & ' \\
\hline 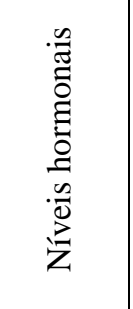 & 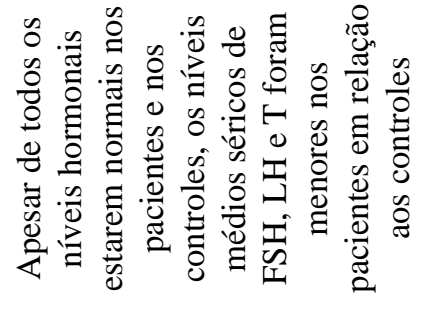 & 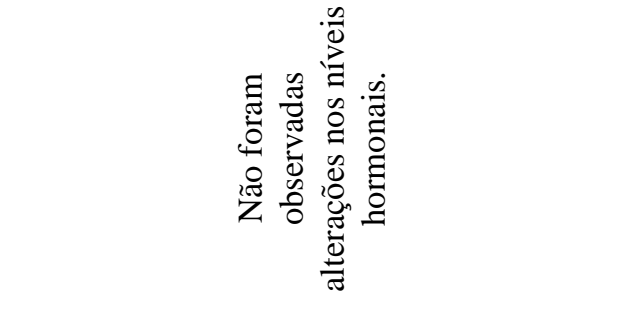 \\
\hline 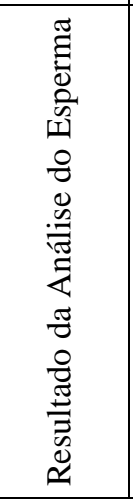 & 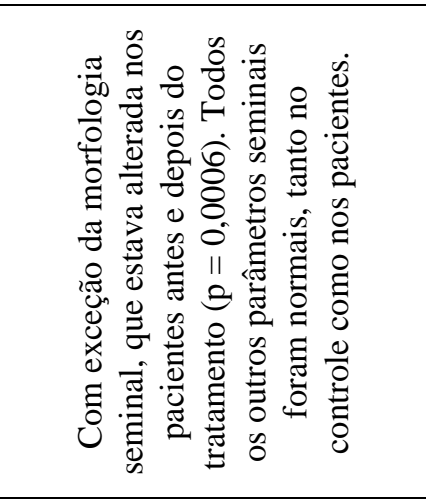 & 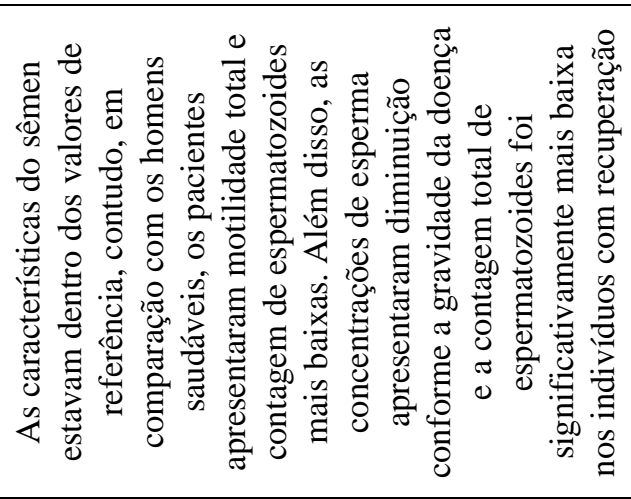 \\
\hline 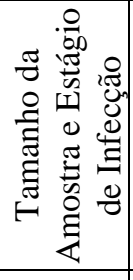 & 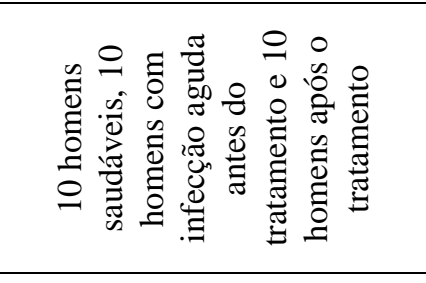 & 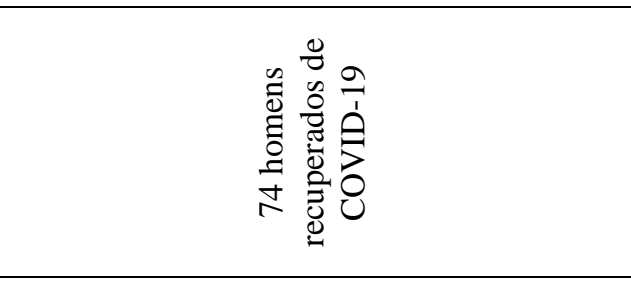 \\
\hline 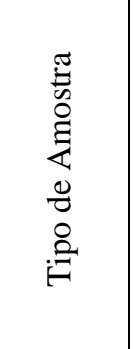 & 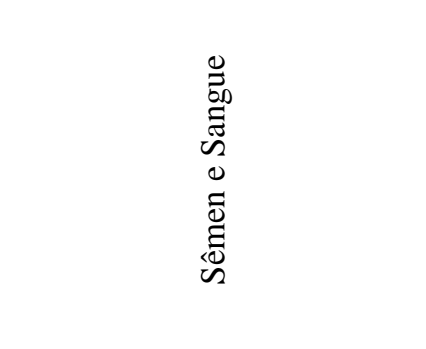 & 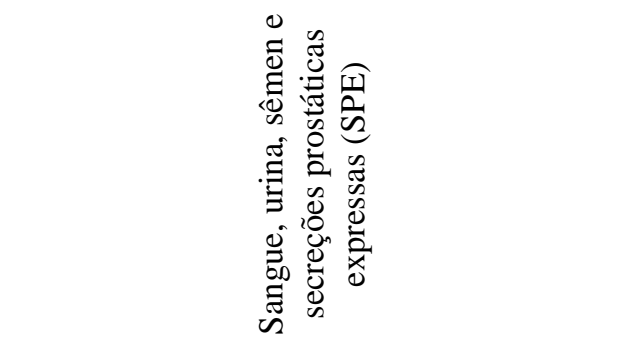 \\
\hline 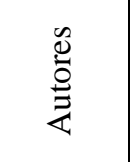 & 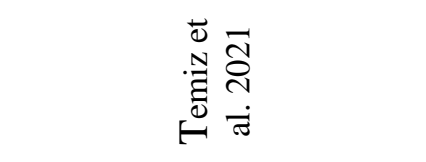 & $\frac{\vec{\sigma}}{\overrightarrow{0}} \overrightarrow{\widetilde{\sigma}}$ \\
\hline
\end{tabular}




\begin{tabular}{|c|c|c|}
\hline 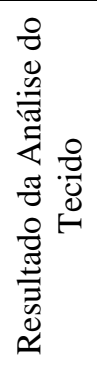 & 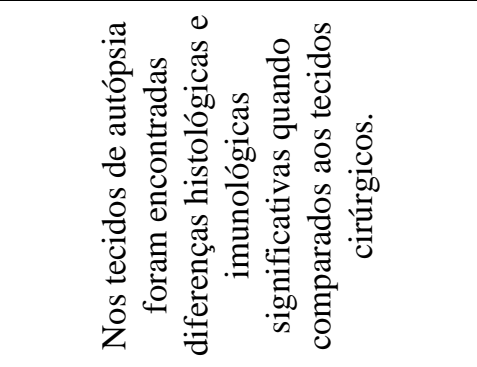 & ' \\
\hline 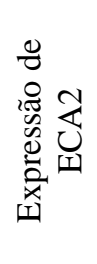 & 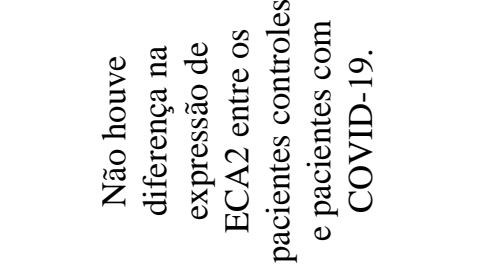 & ' \\
\hline 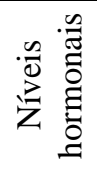 & 1 & ' \\
\hline 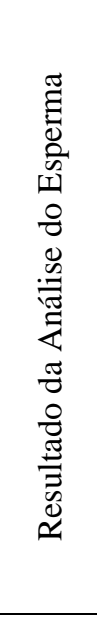 & 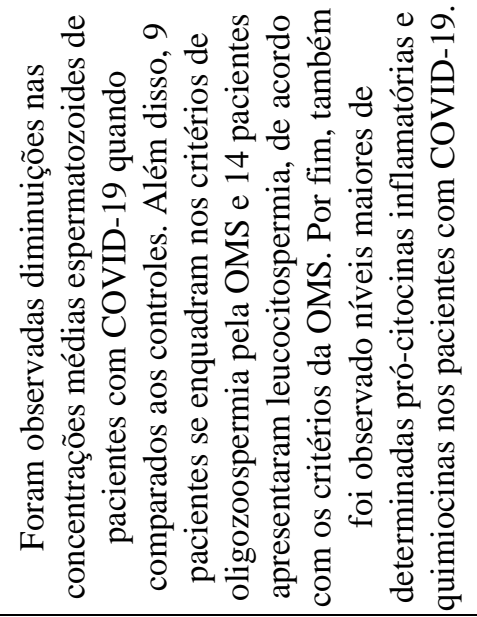 & 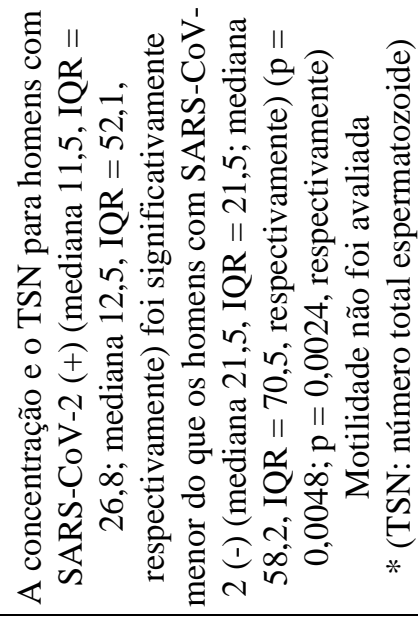 \\
\hline 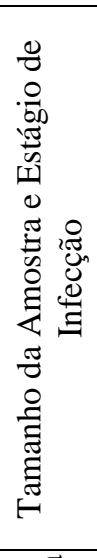 & 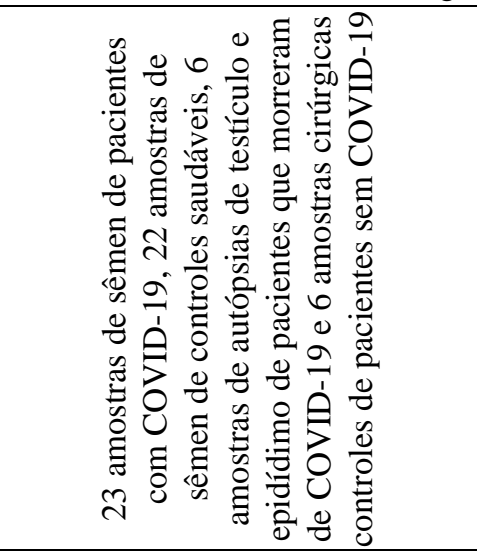 & 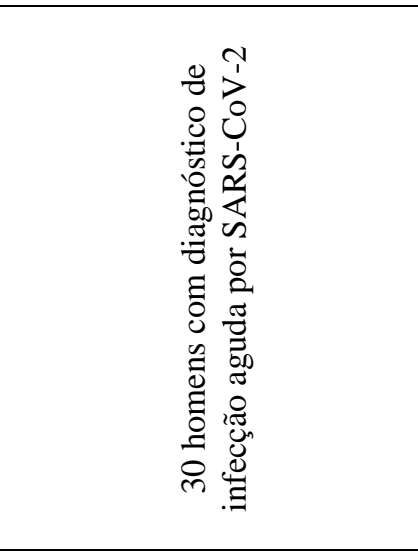 \\
\hline 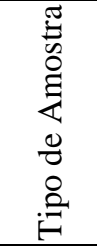 & 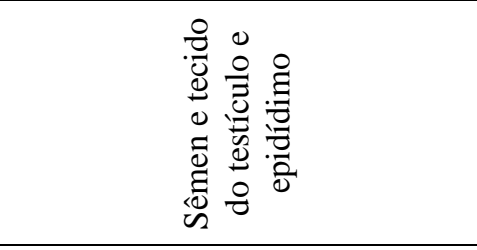 & 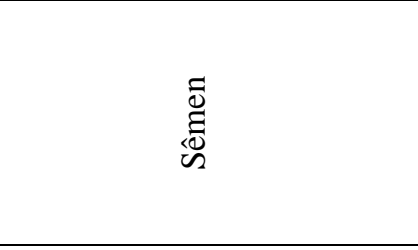 \\
\hline 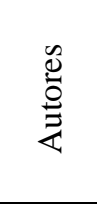 & 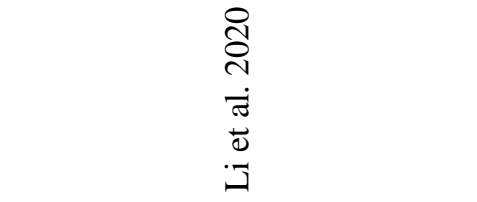 & 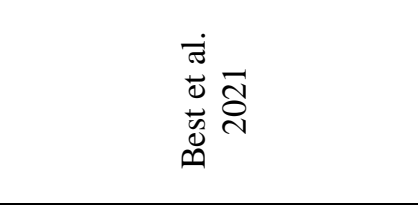 \\
\hline
\end{tabular}




\begin{tabular}{|c|c|c|}
\hline 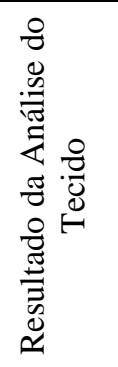 & ' & ' \\
\hline 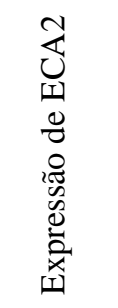 & 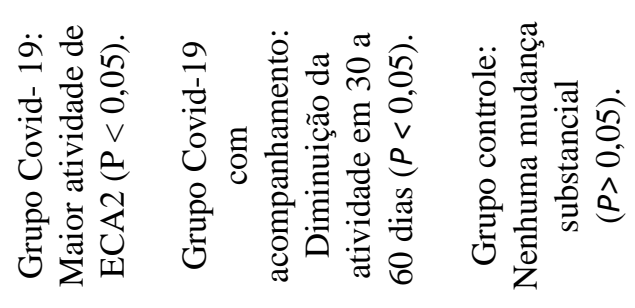 & ' \\
\hline 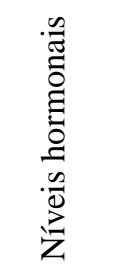 & ' & ' \\
\hline 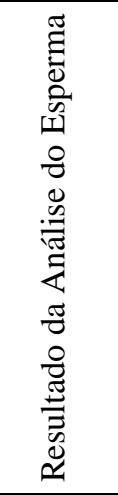 & 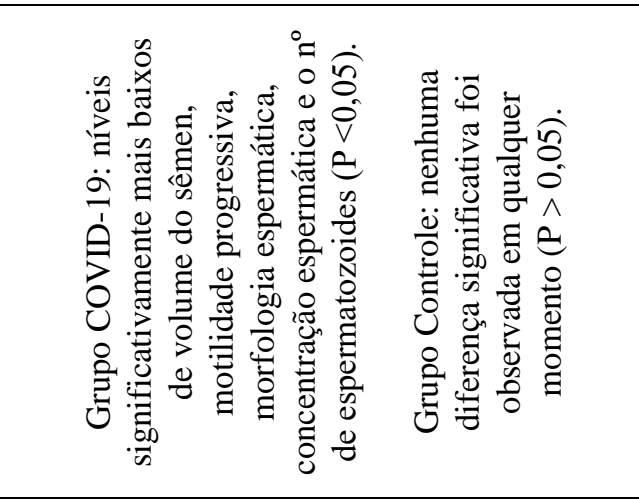 & 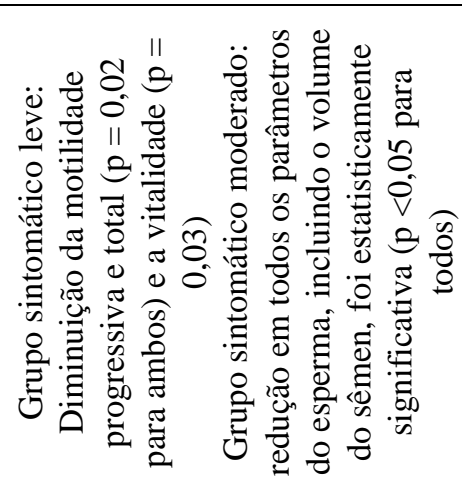 \\
\hline 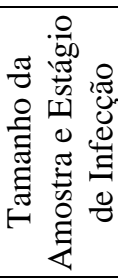 & 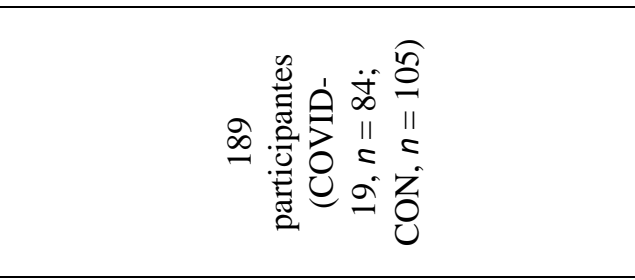 & 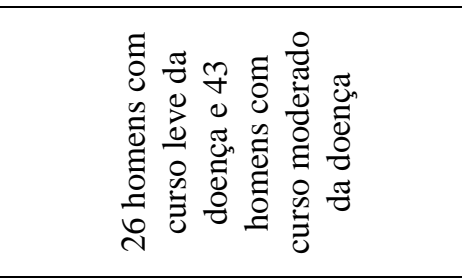 \\
\hline 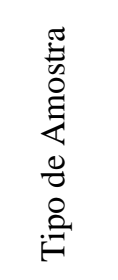 & 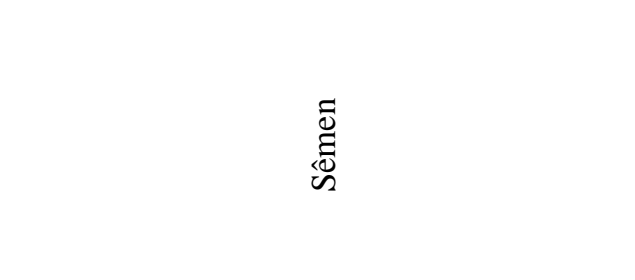 & 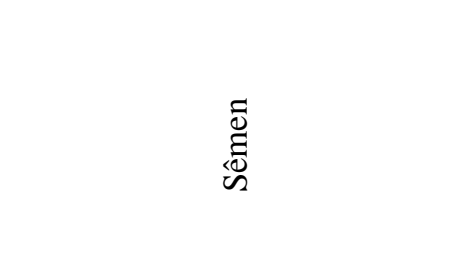 \\
\hline 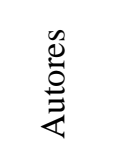 & 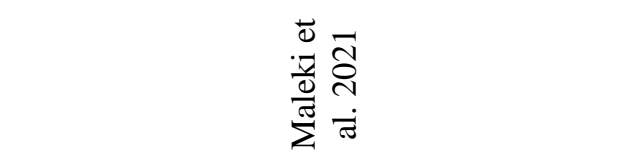 & 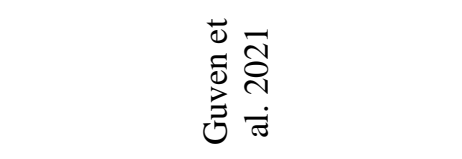 \\
\hline
\end{tabular}


Em 11 de março de 2020, a Organização Mundial da Saúde (OMS) caracterizou a COVID-19 como uma pandemia. Isso motivou a comunidade científica a realizar estudos a fim de compreender a ação do SARS-CoV-2 no organismo humano, tanto nos pacientes com infecção aguda quanto nos recuperados. Sabendo que outras infecções causam impacto no sistema reprodutivo masculino, este estudo buscou verificar se existe alguma relação do COVID-19 com a infertilidade masculina.

Como já explicado anteriormente, a ECA2 é um receptor de SARS-CoV-2 e está presente nas gônadas masculinas ${ }^{6}$. Foi observado que a expressão de ECA2 nas células testiculares diferem em quantidade, e as células de Sertoli são as que apresentam maior proporção de expressão em relação às demais ${ }^{1}$. Relatou-se maior expressão de ECA2 nas células testiculares quando comparadas às células pulmonares, dessa forma, o testículo apresenta grande potencial de infecção pelo vírus, o que pode trazer consequências para a fertilidade masculina ${ }^{5}$.

A alta atividade de ECA2 foi relacionada com a gravidade da doença e piora na qualidade do sêmen ${ }^{7}$. O resultado da análise seminal evidenciou diminuição do volume e concentração do sêmen, diminuição da motilidade espermática, menor número de espermatozoides, além de alterações da morfologia, em pacientes com doença moderada a grave, quando comparados ao grupo controle. Resultados similares foram encontrados em outros dois estudos, entretanto, em um deles as alterações também foram vistas em pacientes com doença leve ${ }^{1,9}$. Todavia, em outro estudo, apenas a morfologia seminal estava alterada nos pacientes, os demais parâmetros foram todos normais, tanto para pacientes quanto para controles ${ }^{10}$. Os pacientes também foram classificados como oligospérmico e com leucospermia, de acordo com os critérios da OMS, devido às diminuições nas concentrações de espermatozoide $^{11}$. Em nenhuma das análises seminais foram encontrados RNA de SARS-CoV-2 $2^{1-7,9-}$ 11.

Com relação às amostras sanguíneas, foram avaliados os níveis hormonais (testosterona, LH e FSH), os quais estavam dentro dos valores de normalidade tanto nos pacientes quanto nos controles, apesar de apresentarem níveis mais baixos em infectados ${ }^{2,10}$.

Ademais, foram analisados tecidos testiculares e epididimários de pacientes que faleceram por COVID-19 comparados com pacientes cirúrgicos sem a doença, sendo observadas diferenças significativas, as quais são: (1) exsudação de hemácias no testículo e epidídimo de dois pacientes falecidos por COVID-19, e no epidídimo de 1 dos pacientes; (2) edema intersticial e congestão no testículo e no epidídimo de todos os pacientes; (3) epitélio seminífero adelgaçado e túbulos seminíferos com maior eliminação epitelial espermatogênica; (4) proporção de células apoptóticas nos tecidos dos pacientes falecidos por COVID-19 2,95 vezes maiores. Com relação aos mediadores imunológicos, observou-se nos tecidos de autópsia: (1) aumento da concentração de linfócitos T e macrófagos no interstício do tecido testicular, ao redor dos vasos e do tecido do epidídimo; (2) linfócitos ocasionais ao redor do ducto epididimal; (3) precipitação de IgG nos túbulos seminíferos de 4 pacientes $^{11}$.

\section{DISCUSSÃO}

Os resultados deste estudo apontam um comprometimento significativo da qualidade seminal pela infecção por SARS-CoV-2, principalmente nos parâmetros de concentração e motilidade espermática. Apesar de, em sua maioria, os pacientes das amostras dos estudos selecionados apresentarem características seminais dentro da normalidade, os valores eram inferiores quando comparados aos de uma população masculina saudável. Ademais, os valores pareceram reduzir ainda mais conforme a gravidade da doença.

O mesmo achado foi observado em relação aos níveis séricos de FSH, LH e T, que apesar de estarem dentro da normalidade em pacientes com histórico de infecção, apresentavam médias 
reduzidas em comparação à população não infectada. Porém, as alterações hormonais não foram vistas em todos os estudos.

Outra divergência encontrada dos estudos foi em relação à expressão de ECA2, que alguns estudos relataram como aumentada em pacientes com COVID-19 e outros relataram não haver diferença quando comparados à pacientes saudáveis.

\section{CONCLUSÃO}

Conclui-se que o testículo é um alvo importante da infecção por SARS-CoV-2, devido à sua alta expressão de ECA2 e de genes relacionados ao vírus. Desta forma, algumas alterações reprodutivas masculinas foram observadas, como diminuições séricas dos hormônios T, FSH e LH e comprometimento da qualidade seminal devido à redução da concentração, mobilidade e contagem de espermatozoides.

Este estudo sugere um impacto da doença na fertilidade masculina, todavia, devido à atualidade do tema, ainda há resultados inconclusivos. São necessários estudos prospectivos concluídos com amostras maiores.

\section{REFERÊNCIAS}

1. Holtmann N, Edimiris P, Andree M, Doehmen C, Baston-Buest D, Adams O, Kruessel JS, Bielfeld AP. Assessment of SARS-CoV-2 in human semen-a cohort study. Fertil Steril [Internet]. 2020 Ago [citado em 2021 setembro 23];114(2):233-238. Disponível em: https://pubmed.ncbi.nlm.nih.gov/32650948/

2. Ruan Y, Hu B, Liu Z, Liu K, Jiang H, Li H, Li R, Luan Y, Liu X, Yu G, Xu S, Yuan X, Wang S, Yang W, Ye Z, Liu J, Wang T. No detection of SARS-CoV-2 from urine, expressed prostatic secretions, and semen in 74 recovered COVID-19 male patients: A perspective and urogenital evaluation. Andrology [Internet]. 2021 Jan [citado em 2021 setembro 23];9(1):99106. Disponível em: https://pubmed.ncbi.nlm.nih.gov/33150723/

3. Pan F, Xiao X, Guo J, Song Y, Li H, Patel DP, Spivak AM, Alukal JP, Zhang X, Xiong C, Li PS, Hotaling JM. No evidence of severe acute respiratory syndrome-coronavirus 2 in semen of males recovering from coronavirus disease 2019. Fertil Steril [Internet]. 2020 Jun [citado em 2021 setembro 23];113(6):1135-1139. Disponível em: https://pubmed.ncbi.nlm.nih.gov/32482249/

4. Best JC, Kuchakulla M, Khodamoradi K, Lima TFN, Frech FS, Achua J, Rosete O, Mora B, Arora H, Ibrahim E, Ramasamy R. Evaluation of SARS-CoV-2 in Human Semen and Effect on Total Sperm Number: A Prospective Observational Study. World J Mens Health [Internet]. 2021 Jul [citado em 2021 setembro 23];39(3):489-495. Disponível em: https://pubmed.ncbi.nlm.nih.gov/33663031/

5. Shen Q, Xiao X, Aierken A, Yue W, Wu X, Liao M, Hua J. The ACE2 expression in Sertoli cells and germ cells may cause male reproductive disorder after SARS-CoV-2 infection. J Cell Mol Med [Internet]. 2020 Ago [citado em 2021 setembro 23];24(16):9472-9477. Disponível em: https://pubmed.ncbi.nlm.nih.gov/32594644/

6. Liu X, Chen Y, Tang W, Zhang L, Chen W, Yan Z, Yuan P, Yang M, Kong S, Yan L, Qiao J. Single-cell transcriptome analysis of the novel coronavirus (SARS-CoV-2) associated gene ACE2 expression in normal and non-obstructive azoospermia (NOA) human male testes. Sci China Life Sci [Internet]. 2020 Jul [citado em 2021 setembro 23];63(7):1006-1015. Disponível em: https://pubmed.ncbi.nlm.nih.gov/32361911/

7. Hajizadeh Maleki B, Tartibian B. COVID-19 and male reproductive function: a prospective, longitudinal cohort study. Reproduction [Internet]. 2021 Mar [citado em 2021 setembro 23];161(3):319-331. Disponível em: https://pubmed.ncbi.nlm.nih.gov/33522983/ 
8. Boopathi S, Poma AB, Kolandaivel P. Novel 2019 coronavirus structure, mechanism of action, antiviral drug promises and rule out against its treatment. J Biomol Struct Dyn [Internet]. 2021 Jun [citado em 2021 setembro 23]; 39(9):3409-3418. Disponível em: https://pubmed.ncbi.nlm.nih.gov/32306836/

9. Erbay G, Sanli A, Turel H, Yavuz U, Erdogan A, Karabakan M, Yaris M, Gultekin MH. Short-term effects of COVID-19 on semen parameters: A multicenter study of 69 cases. Andrology [Internet]. 2021 Jul [citado em 2021 setembro 23];9(4):1060-1065. Disponível em: https://pubmed.ncbi.nlm.nih.gov/33851521/

10. Temiz MZ, Dincer MM, Hacibey I, Yazar RO, Celik C, Kucuk SH, Alkurt G, Doganay L, Yuruk E, Muslumanoglu AY. Investigation of SARS-CoV-2 in semen samples and the effects of COVID-19 on male sexual health by using semen analysis and serum male hormone profile: A cross-sectional, pilot study. Andrologia [Internet]. 2021 Mar [citado em 2021 setembro 23];53(2):e13912. Disponível em: https://pubmed.ncbi.nlm.nih.gov/33244788/

11. Li H, Xiao X, Zhang J, Zafar MI, Wu C, Long Y, Lu W, Pan F, Meng T, Zhao K, Zhou L, Shen S, Liu L, Liu Q, Xiong C. Impaired spermatogenesis in COVID-19 patients. EClinicalMedicine [Internet]. 2020 Nov [citado em 2021 setembro 23];28:100604. Disponível em: https://pubmed.ncbi.nlm.nih.gov/33134901/f 